\title{
Chronic alcohol consumption from adolescence- to-adulthood in mice - hypothalamic gene expression changes in the dilated cardiomyopathy signaling pathway
}

Hong Zou ${ }^{1,2}$, Ke Wang ${ }^{3,4}$, Yang Gao ${ }^{3}$, Huaiguang Song ${ }^{3}$, Qinglian Xie ${ }^{1}$, Meilei Jin ${ }^{1}$, Guoping Zhao ${ }^{1,2,35^{*}}$, Huasheng $\mathrm{XiaO}^{3^{*}}$ and Lei $\mathrm{Yu}^{6^{*}}$

\begin{abstract}
Background: Adolescence is a developmental stage vulnerable to alcohol drinking-related problems and the onset of alcoholism. Hypothalamus is a key brain region for food and water intake regulation, and is one of the alcohol-sensitive brain regions. However, it is not known what would be the alcohol effect on hypothalamus following adolescent alcohol intake, chronically over the adolescent development, at moderate levels.

Results: We employed a paradigm of chronic moderate alcohol intake from adolescence-to-adulthood in mice, and analyzed the alcohol effect on both behavioral and hypothalamic gene expression changes. A total of 751 genes were found and subjected to pathway analysis. The dilated cardiomyopathy (DCM) pathway was identified. The changes of ten genes under this pathway were further verified using RT-PCR. Chronic alcohol consumption during adolescence, even at moderate levels, led to a decrease of motor activity in mice, and also a concerted down regulation of signaling pathway initiating factor (SPIF) genes in the DCM signaling pathway, including $\beta 1$-adrenergic receptor (Adrb1), Gs protein (Gnas), adenylyl cyclase 1 (Adcy1), and dihydropyridine receptor/L-type calcium channel (Cacna1d).

Conclusions: These findings suggest that adolescent alcohol intake may trigger gene expression changes in the CNS that parallel those found in the dilated cardiomyopathy signaling pathway. If such effects also take place in humans, our findings would serve as a warning against alcohol intake in youth, such as by teens and/or college students.
\end{abstract}

Keywords: Chronic alcohol drinking, Self-administration, Adolescence, Mice, Gene expression, Hypothalamus

\section{Background}

Adolescence is a critical transitional stage during which youth mature into adulthood. This developmental stage is characterized by a continued brain remodeling, a process that is sensitive to the disrupting effects of alcohol $[1,2]$. Epidemiological studies indicate that adolescence is

\footnotetext{
*Correspondence: gpzhao@sibs.ac.cn; huasheng_xiao@shbiochip.com; yu@biology.rutgers.edu

${ }^{1}$ Shanghai Institutes for Biological Sciences, Chinese Academy of Sciences, Shanghai, China

${ }^{3}$ Shanghai-MOST Key Laboratory of Disease and Health Genomics, Chinese National Human Genome Center at Shanghai, National Engineering Research Center for Biochip at Shanghai, Shanghai, China

${ }^{6}$ Department of Genetics \& Center of Alcohol Studies, Rutgers University, 607 Allison Road, Piscataway, New Jersey 08854, USA

Full list of author information is available at the end of the article
}

a developmental stage particularly vulnerable to alcohol drinking-related problems and the onset of alcoholism [3-7].

The brain is one of the major target organs of alcohol. Excessive alcohol exposure can lead to structural and functional changes of the brain [8-11], resulting in malfunctioning of the CNS activity, as well as deleterious influence of bodily function [12-14].

Hypothalamus is one of the alcohol-sensitive brain regions [15]. Being a key brain region for food and water intake regulation [16-18] and part of the reward system [19-21], the hypothalamus can modulate alcohol consumption and is involved in the development of alcoholism. It has been shown that stimulation of lateral hypothalamic

\section{Biomed Central}


regions could trigger alcohol consumption [22,23]. Neuropeptides that are found in the hypothalamus could stimulate alcohol intake [24-26].

Conversely, alcohol can also affect hypothalamic activities. Alcohol is known to activate the HPA axis [27-29]. It is likely that by modifying the activity of the HPA axis, alcohol will influence, and possibly compromise, the ability of the body to maintain or restore homeostasis and to coordinate appropriate behavioral responses in response to stressors [30]. In alcohol-dependent subjects, dopamine D3 receptor (DRD3) binding in the hypothalamus was increased [31]. Alcohol alters genes expression of LHRH secretory pathway in the hypothalamus of prepubertal female rats, resulting in suppressed LHRH secretion and delayed puberty [32,33]. The expression of hypothalamic proopiomelanocortin (POMC) gene was reduced by prenatal exposure to alcohol in rats [34], and the POMC expression reduction persisted into adulthood by postnatal alcohol feeding in mice [35]. The expression of Fos-related immediate early genes was altered following chronic alcohol administration in mice and rats [15,36,37].

Aside from alcohol, other substances of abuse potential have been shown to influence gene activity in the hypothalamus. Thus, cocaine increased POMC gene expression in rat hypothalamus [35], and escalated cocaine intake correlated with a number of genes in the lateral hypothalamic regions [38]. Nicotine exposure was shown to affect brain development, corresponding to abnormal hypothalamic gene expression of appetite regulators such as down-regulation of NPY and POMC in the arcuate nucleus of the hypothalamus [39].

Hypothalamus also plays a role in autonomic modulation of cardiovascular system. Sympathetic nervous system can also be activated by alcohol, and chronic exposure of the heart to elevated catecholamine levels released from sympathetic nerve terminals may result in pathological changes of the heart $[40,41]$.

Studies of the effect of chronic alcohol exposure on the hypothalamus have been limited, particularly at the level of gene expression changes. Specifically, it is not known what would be the alcohol effect on hypothalamus following adolescent alcohol intake, chronically over the adolescent development, at moderate levels. In the present study, we employed a paradigm of chronic moderate alcohol intake from adolescence-to-adulthood in mice [42], and report here the alcohol effect on both behavioral and hypothalamic gene expression changes.

\section{Results}

\section{Chronic alcohol consumption}

We used a two-bottle free-choice paradigm to measure alcohol drinking [42], and studied effect of chronic alcohol consumption during adolescent development. Male adolescent mice ( 3 weeks of age) were divided into two
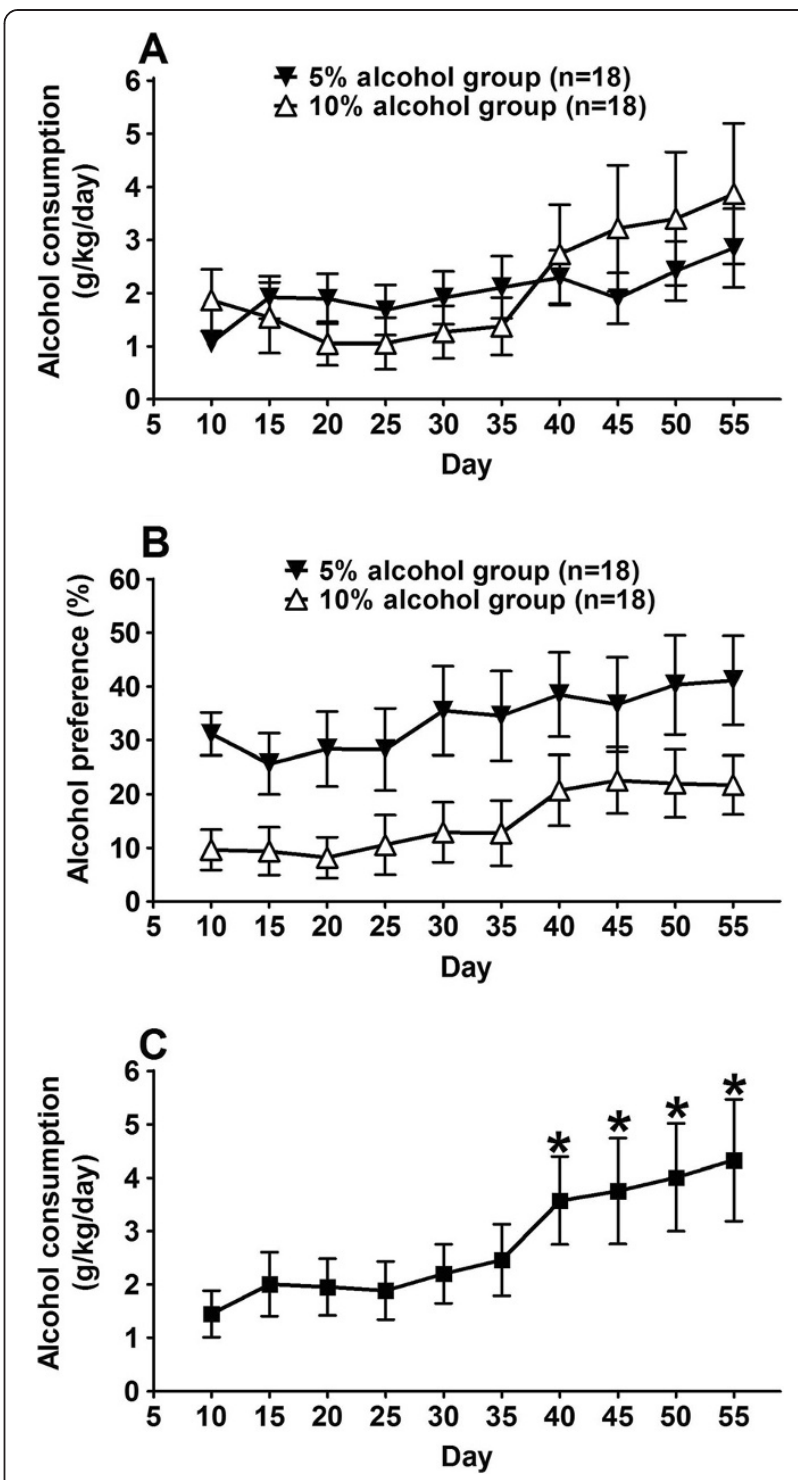

Figure 1 Chronic self-administration of alcohol in mice during adolescence. (A) Adolescent mice (3 weeks old) had free access to water and alcohol solutions. Two alcohol groups were used; one group had 5\% alcohol (filled triangles), and the other had 10\% alcohol (open triangles). Data are shown for daily alcohol consumption (grams of alcohol per kilogram mouse body weight per day, average over 5 days). Data are expressed as mean \pm S.E.M. ( $n=18$ for each group). There was no statistically significant difference between the two groups at any time point ( $p>0.05$, two-way ANOVA with Bonferroni post-test). (B) Alcohol preference over water $(\% \mathrm{~V} / \mathrm{V})$, from the same mouse alcohol groups as in (A), showing that mice from the $5 \%$ alcohol group consumed higher volume of alcohol solution than those from the 10\% alcohol group. The average amounts of alcohol consumed by the $5 \%$ vs. $10 \%$ groups were not significantly different. (C) Alcohol consumption data of the mice used for microarray gene expression study. Mice used for the gene expression study were selected from the $5 \%(n=9)$ and $10 \%(n=10)$ alcohol group, respectively. Data are expressed as mean \pm S.E.M. $(n=19)$. A steady increase of alcohol consumption was present, as the alcohol consumption data from later time points (day 40 and later) are significantly different from the data at the beginning $(p<0.05$, Repeated measures ANOVA with post test of Dunnett's multiple comparison test). 
alcohol groups, one with free access to 5\% alcohol, and the other to $10 \%$ alcohol, so as to determine if there was a difference in alcohol consumption behavior due to difference in alcohol concentration. In addition, a wateronly control group (each mouse had 2 bottles, both filled with water) was used. Figure 1A showed the results of daily alcohol consumption (grams of alcohol per kilogram mouse body weight per day, average over 5 days) for the $5 \%$ alcohol group $(n=18)$ and the $10 \%$ alcohol group $(\mathrm{n}=18)$. Both groups of mice consumed similar amounts of alcohol, and there was no statistically significant difference $(\mathrm{F}(1,306)=0.1292, \mathrm{p}=0.7215$, two-way ANOVA with Bonferroni post-test). Figure $1 \mathrm{~B}$ plotted alcohol preference (alcohol volume over water) from the same mouse alcohol groups, showing that mice from the $5 \%$ alcohol group consumed higher volume of alcohol solution than those from the $10 \%$ alcohol group. Since the $10 \%$ alcohol solution contained higher amount of alcohol per unit volume than the $5 \%$ alcohol solution, we calculated the absolute amounts of alcohol consumption by mice from both the $5 \%$ alcohol group and the $10 \%$ alcohol group, and found that there was no significant difference for the absolute amount of alcohol consumed between the $5 \%$ vs. $10 \%$ alcohol groups.

Because there was no significant difference for the daily alcohol consumption between the 5\% and the $10 \%$ alcohol groups, we combined mice from the $5 \%$ and $10 \%$ alcohol groups, to analyze the overall pattern of alcohol consumption (Figure 1C). Over the course of adolescent alcohol exposure, a trend of increased alcohol consumption was observed, with alcohol consumption data from later time points (day 40 and later) significantly different from those in the earlier time points $(\mathrm{p}<0.05$, repeated measures ANOVA with post test of Dunnett's multiple comparison test). Average daily alcohol consumption over the duration of the entire procedure (50 days) was $2.8 \mathrm{~g} / \mathrm{kg} /$ day, and for the last 5 days (day $50-55$ ) it was $4.3 \mathrm{~g} / \mathrm{kg} /$ day. These amounts of daily alcohol consumption represent a moderate level of alcohol consumption (see Discussion).

Evaluation of motor activities indicated that chronic alcohol mice displayed accelerated acclimation for motor activities (Figure 2). This is consistent with reported alcohol exposure-induced locomotor activity changes [43-45].

Gene expression changes after chronic alcohol exposure For brain tissue processing for gene expression analysis, 19 mice with 7 weeks alcohol exposure were selected and grouped into alcohol sample groups $(n=1-3$ per sample group). Samples A1-A3 had mice with relatively less alcohol consumed $(0.50 \pm 0.38 \mathrm{~g} / \mathrm{kg} /$ day $)$; samples A4-A9 had mice with relatively more alcohol consumed (4.80 \pm $0.36 \mathrm{~g} / \mathrm{kg} /$ day); these were significantly different $(\mathrm{p}<0.05$, Unpaired t test with Welch's correction). The rationale for
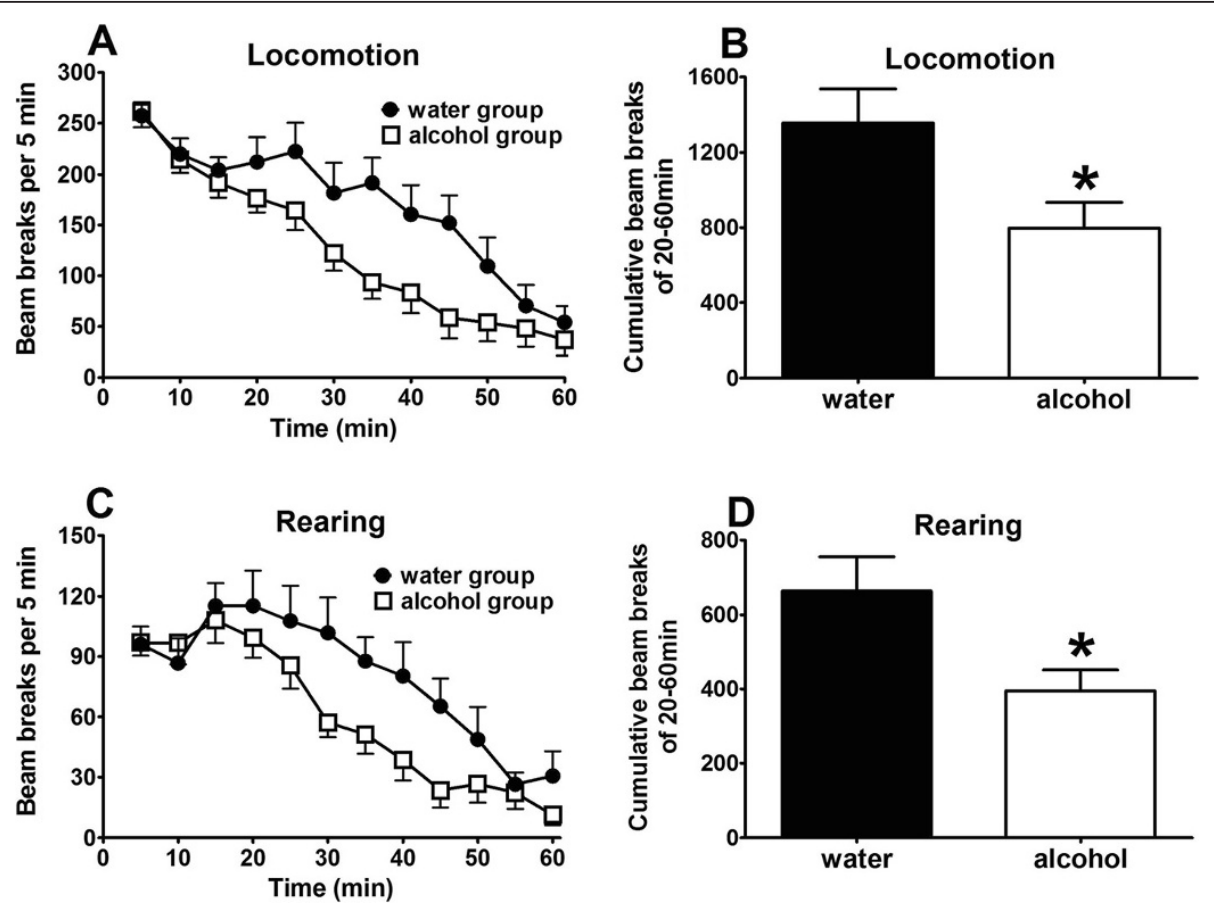

Figure $\mathbf{2}$ Chronic alcohol consumption leads to a decrease of motor activity in mice. Upper panels (A and $\mathbf{B}$ ): locomotion; lower panels $(\mathbf{C}$ and $\mathbf{D})$ : rearing. Time course of locomotion $(\mathbf{A})$ and rearing $(\mathbf{C})$ are shown as beam breaks per 5 min. Cumulative locomotion (B) and rearing (D) for the entire period (0-60 min) are shown. Data are expressed as mean \pm S.E.M. ( $n=19$ for the alcohol group, $n=8$ for the water-only control group). *, significant difference compared with the water-only control group $(p<0.05$, unpaired t-test). 
such an approach of sample pooling was to cover the spectrum of mouse alcohol consumption behavior, so that the underlying gene expression patterns may be discernible. For water-only controls, nine mice were selected randomly, and grouped into water sample groups $(n=3$ per sample group), designated samples C1-C3.

RNA samples extracted from hypothalamus were used in gene expression analysis, using the Agilent mouse whole genome microarray chip set. Data from all probe sets (after passing through the filters for high-quality array data, see Methods) were used in principal component analysis (PCA). Results of PCA were shown in Figure 3, showing different distribution patterns of alcohol mice vs. water mice. For component A from PCA, both water controls and chronic alcohol mice showed results centered around the 0 axis. However, while the component A results from water samples were tightly grouped around the 0 axis, that from chronic alcohol mice were spread more widely, indicating more heterogeneity in gene expression represented in component A. For component B, results from water controls were tightly grouped above positive 50 level, while most (except sample A1) alcohol samples were near (sample A6) or in the negative value range. The distribution pattern highlighted the fact that chronic alcohol consumption mice had very different gene expression patterns compared to the water controls, indicating that chronic alcohol exposure during adolescent development lead to altered gene expression in the hypothalamus.

Significant differences in gene expression were observed between chronic alcohol exposure and water controls, with 1900 regulated probes representing 1819 genes (890 up-regulated and 929 down-regulated, chronic alcohol relative to water controls) using the $t$-test at the $p<0.05$

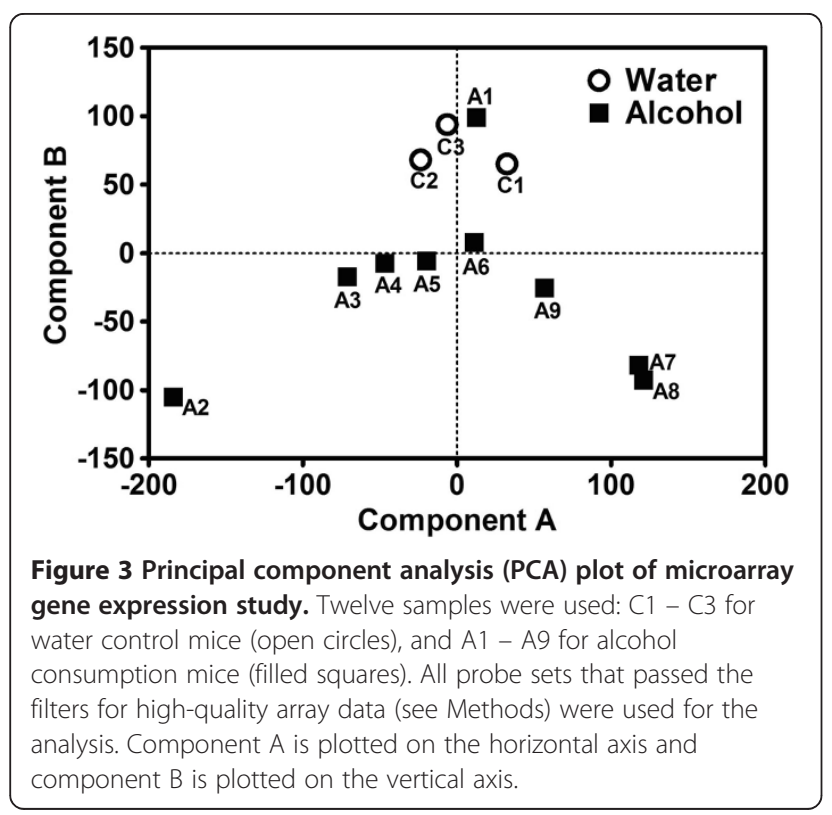

(Additional file 1: Table S1 and Additional file 2: Figure S1). Unsupervised hierarchical clustering analysis based on these differentially expressed genes also showed distinct clustering of the alcohol hypothalamus samples compared with control hypothalamus samples (Figure 4 and Additional file 2: Figure S1).

\section{Pathway analysis of differentially expressed genes}

Of the 1819 differentially expressed genes, 340 genes showed less than 0.83 fold change (representing 20\% down-regulation of chronic alcohol exposure relative to water control) and 411 genes showed more than 1.2 fold change (representing 20\% up-regulation of chronic alcohol exposure relative to water control). These 751 genes were chosen for pathway analysis, and several pathways were identified (Additional file 3: Table S4). One pathway showed $p<0.01$ - the dilated cardiomyopathy pathway, from the pathway enrichment analysis by both DAVID Functional Classification Analysis and Web-based Gene Set Analysis, and was chosen for further studies.

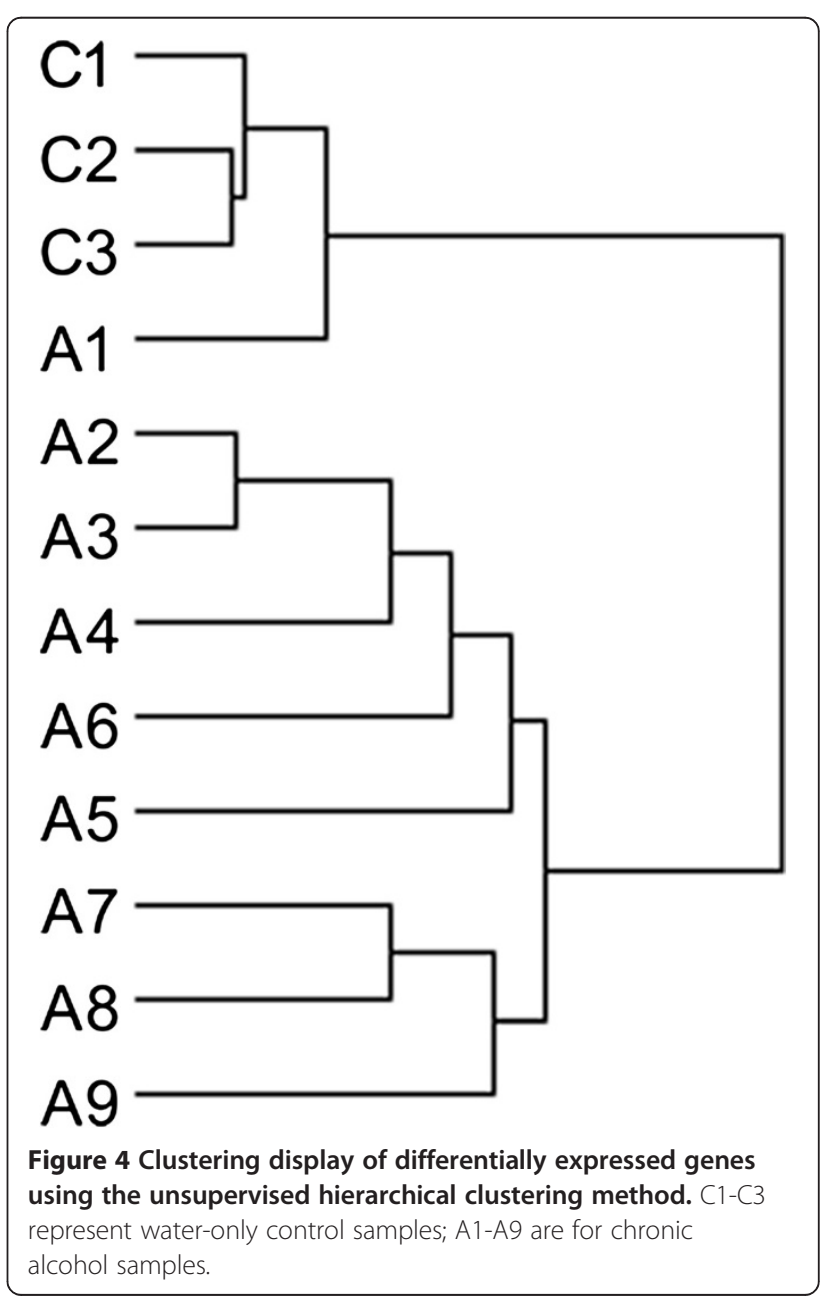




\section{Validation of microarray results by real-time PCR}

To provide independent validation of the identified gene pathway from microarray analysis of gene expression data, real-time PCR was used to measure gene expression level changes with the same RNA samples used in the microarray experiment. We studied ten genes in the dilated cardiomyopathy (DCM) pathway that were identified as differentially expressed genes $(\mathrm{p}<0.05$, showing $20 \%$ up- or down-regulation), as well as two other genes in the DCM pathway with "borderline" difference (Adrb1, $\mathrm{p}<0.06,0.78$-fold change; Prkx, $\mathrm{p}<0.03,0.94$-fold change) because of their key positions in the DCM pathway; in addition, Jup was tested, as an internal control, because it was among those identified by microarray analysis, but was not situated in the $\beta 1$ AR-DHPR-Ca ${ }^{2+}$ branch of the DCM pathway. Seven candidate genes among the thirteen tested were validated by real-time PCR as differentially expressed genes, giving a $53.8 \%$ positive confirmation rate. Table 1 lists the seven genes that showed significantly differentiated expression between the chronic alcohol samples and the water control samples: Adrb1, Gnas, Adcy1, Cacna1d, and Itga4 with down-regulation, while Des and Igf1 with upregulation. Interestingly, the four genes with the strongest statistical difference (Adrb1, Gnas, Adcy1, and Cacna1d) all showed down-regulation, and they all code for proteins which initiate the signaling steps in the B1AR-DHPR-Ca ${ }^{2+}$ branch of the DCM pathway (see diagram in Figure 5), suggesting that this branch may be impacted by chronic alcohol consumption during adolescence.

\section{Discussion}

In this study, we used mice to study chronic alcohol consumption during adolescence and its effect on gene expression and behavior in adulthood. We selected ICR mice for this study, instead of the more commonly used C57BL6 mice, for two reasons: (1) ICR mouse is an outbred mouse strain with inter-individual variability - similar to the outbred nature of humans. Using an outbred mouse strain such as ICR to study alcohol effect would more closely model the effect of alcohol in humans. (2) As an inbred strain, C57BL6 mice are known to drink considerably more alcohol than other mouse strains [46]. Thus, C57BL6 mice may represent only a special case regarding alcohol drinking behavior. Outbred mice such as ICR have been shown to consume less alcohol and exhibit lower preference for alcohol than C57BL6 mice [47]; in a preference test with $3 \%-30 \%$ alcohol, the mean maximally preferred concentrations of alcohol were approximately $18 \%$ for C57BL6 mice vs. 7\% for ICR mice [48]. We chose a two-bottle free-choice paradigm to measure alcohol drinking, as animals have unrestricted access to both water and alcohol for their own choice, thus better modeling the free-choice nature of human access to alcohol; such an approach has been used to identify the genetic basis for alcohol preference and dependence [49-56].

In our study, mice started chronic alcohol drinking from the age of about 4 weeks old and lasted seven weeks, covering the entire period of adolescence-toadulthood development in mice. During this time, a trend of increased alcohol consumption was observed (Figure 1C), with an overall average alcohol consumption of $2.8 \mathrm{~g} / \mathrm{kg} /$ day. This represents a moderate level of alcohol consumption, as it is comparable to the lower range of alcohol intake in a cross-mouse strain study of alcohol intake during the 4-hour daily drinking session using the drinking-in-the-dark model [46]. Using FDA's

Table 1 RT-PCR confirmation of differential gene expression in hypothalamus between alcohol and water groups

\begin{tabular}{|c|c|c|c|c|c|}
\hline Gene symbol & Gene name & Microarray p-value & Microarray fold change & RT-PCR p-value & RT-PCR fold change \\
\hline Cacna1d & $\begin{array}{l}\text { Calcium channel, voltage-dependent, } \\
\text { L type, alpha 1D subunit }\end{array}$ & $0.005^{*}$ & 0.748 & $0.0003^{*}$ & 0.609 \\
\hline Gnas & $\begin{array}{l}\text { GNAS (guanine nucleotide binding protein, } \\
\text { alpha stimulating) complex locus }\end{array}$ & $0.006^{*}$ & 0.586 & $0.001^{*}$ & 0.604 \\
\hline Adrb1 & Adrenergic receptor, beta 1 & 0.062 & 0.781 & $0.007^{*}$ & 0.815 \\
\hline Adcy1 & Adenylate cyclase 1 & $0.030^{*}$ & 0.824 & $0.016^{*}$ & 0.517 \\
\hline Itga4 & Integrin alpha 4 & $0.011^{*}$ & 0.634 & $0.021^{*}$ & 0.734 \\
\hline Adcy3 & Adenylate cyclase 3 & $0.024^{*}$ & 1.103 & 0.342 & 0.896 \\
\hline Prkx & Protein kinase, $\mathrm{X}$-linked & $0.033^{*}$ & 0.940 & 0.477 & 0.812 \\
\hline Cacnb4 & $\begin{array}{l}\text { Calcium channel, voltage-dependent, } \\
\text { beta } 4 \text { subunit }\end{array}$ & $0.017^{*}$ & 1.085 & 0.377 & 0.911 \\
\hline lgf1 & Insulin-like growth factor & $0.012^{*}$ & 1.214 & $0.036^{*}$ & 1.284 \\
\hline Des & Desmin & $0.004^{*}$ & 1.488 & $0.044^{*}$ & 1.367 \\
\hline Sgcd & $\begin{array}{l}\text { Sarcoglycan, delta (dystrophin-associated } \\
\text { glycoprotein) }\end{array}$ & $0.013^{*}$ & 1.568 & 0.084 & 1.251 \\
\hline Tnni3 & Troponin I, cardiac 3 & $0.041^{*}$ & 1.401 & 0.232 & 1.272 \\
\hline
\end{tabular}

${ }^{*} p<0.05$. 


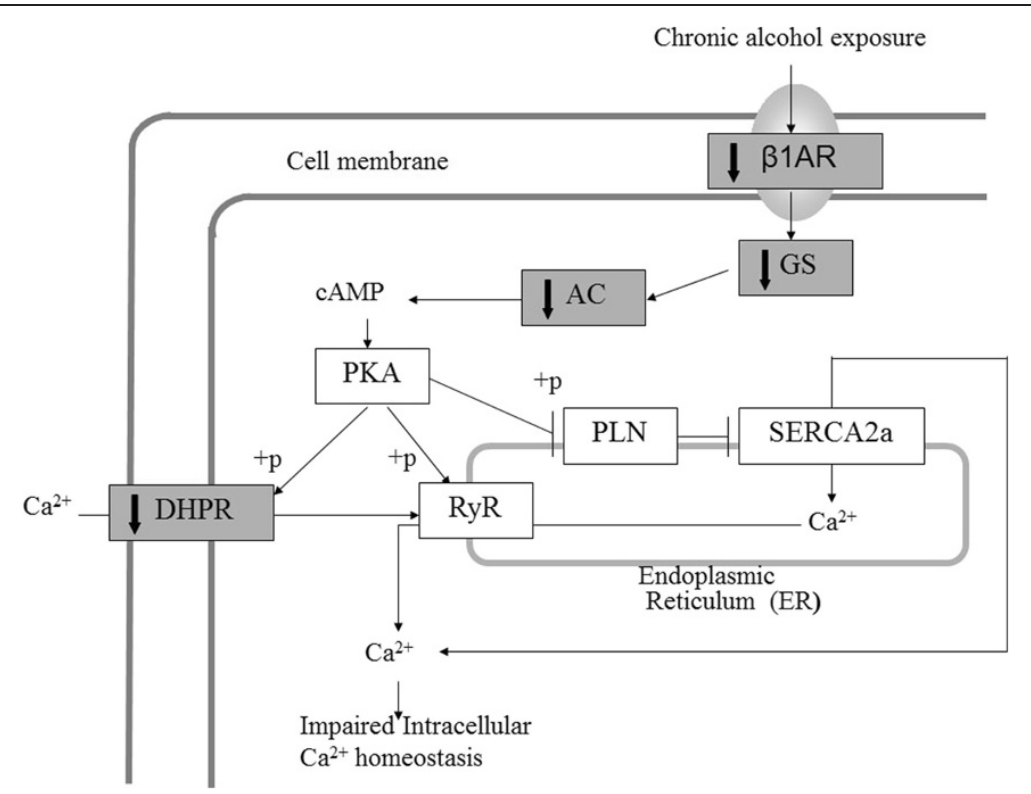

Figure 5 Hypothesis of adolescent chronic alcohol consumption effect on SPIF gene down regulation in the dilated cardiomyopathy signaling pathway. Diagram was adapted from KEGG pathway (http://www.genome.jp/kegg/) [92] for dilated cardiomyopathy (DCM), showing the $\beta 1$ AR-DHPR-Ca ${ }^{2+}$ branch of the DCM pathway. Adolescent chronic alcohol consumption is hypothesized to result in the down regulation of SPIF genes (marked with grey color and solid down arrows), including $\beta 1$-adrenergic receptor (Adrb1), Gs protein (Gnas), adenylyl cyclase 1 (Adcy1), and dihydropyridine receptor/L-type calcium channel (Cacna1d). The coordinated down regulation of these SPIF genes leads to impaired intracellular $\mathrm{Ca}^{2+}$ homeostasis at the cellular level.

guidance for conversion of animal doses to human equivalent doses (HED) based on body surface area [57], this level of alcohol consumption in mouse is roughly equivalent to about 1-2 glasses of wine in a $60 \mathrm{~kg}$ adult human. Interestingly, such a relatively moderate level of alcohol drinking during adolescent development still resulted in a pattern of gene expression change in hypothalamus; in particular, for certain genes that have been shown to be involved in the dilated cardiomyopathy (Figure 5).

\section{Adolescent chronic alcohol intake in mice results in a pattern of gene regulation in the hypothalamus}

Our results showed that chronic alcohol intake influences hypothalamic gene expression. From our microarray analysis of hypothalamic gene expression, 1,819 genes showed significant changes, of which 751 displaying gene expression change of 1.2 fold or higher. PCA (Figure 3 ) and clustering analysis (Figure 4) showed that, compared with water controls, alcohol intake in mice displayed a pattern of hypothalamic gene expression changes. Using pathway analysis of the differentially expressed genes, we found that dilated cardiomyopathy (DCM) pathway is one of the major pathways that was affected by chronic alcohol intake. Using RT-PCR, five genes in the DCM pathway (Adrb1, Gnas, Adcy1, Cacna1d, and Itga4) are downregulated in chronic alcohol mice relative to water controls, and two genes were up-regulated (Des and Igf1)
(Table 1). Of the five down-regulated genes, four of them (Adrb1: $\beta-1$ adrenergic receptor, $\beta 1 \mathrm{AR}$; Gnas: guanine nucleotide binding protein, alpha stimulating, Gs $\alpha$; Adcy1: adenylyl cyclase 1, AC1; and Cacna1d: calcium channel, voltage-dependent, L type, alpha 1D subunit, D-LTCCs) belong to the $\beta 1 A R-D H P R-C a^{2+}$ branch of the DCM pathway (Figure 5). The functions of these gene products are closely related: $\beta$-adrenergic receptors are coupled to $\mathrm{G}$ proteins including Gnas, which stimulates adenylyl cyclase, and results in increased cAMP levels. The primary target for cAMP is protein kinase $\mathrm{A}$, which phosphorylates several proteins including Cacna1d, which regulates $\mathrm{Ca}^{2+}$ influx into the cytosol from intracellular $\mathrm{Ca}^{2+}$ stores endoplasmic reticulum in neurons and sarcoplasmic reticulum in cardiac myocytes. What these genes share in common is that they all code for proteins which initiate the signaling steps of this pathway. Thus, we term these gene products "signaling pathway initiating factors" (SPIFs).

Our results corroborate with evidence from human and rodent studies where chronic alcohol treatment was used. In human, chronic alcoholism was shown to be related to the reduced Gs $\alpha$ levels in the temporal cortices of postmortem brains [58]. Also, postmortem brains of alcoholics showed a significant reduction of adenylyl cyclase 1 in both frontal and temporal cortices [59]. In addition, adenylyl cyclase mRNA levels in the blood were significantly lower in alcoholics than in controls [59]. Cyclic 
AMP levels were also decreased in lymphocytes of alcoholics [60]. Some of these molecular effects appear longlasting. For example, in platelet membranes, adenylyl cyclase activity was lower in alcoholics who had abstained from alcohol for one to four years [61].

In rodents treated with chronic alcohol, it has been shown that in myocardial membranes, $\beta$-adrenergic receptor and cAMP levels were decreased [62], similar to our observations at the mRNA levels of these proteins (Table 1). In addition, $\beta$-adrenergic receptor density in the heart was decreased by alcohol exposure [63]. There are also ample evidence of chronic alcohol-related reduction in rodents for adenylyl cyclase and $G$ proteins in the CNS, including cerebral cortex [64,65], pituitary [66], and cerebellum and pons [67]. These reports demonstrate that chronic alcohol treatment in vivo show a consistent pattern of reduction in $\beta-1$ adrenergic receptor, $\mathrm{G}$ protein, and adenylyl cyclase, consistent with our observations for the SPIFs, and suggesting that alcoholinduced impairment of these SPIFs may represent a rather common pathophysiological outcome from chronic alcohol exposure.

Of the down-regulated SPIF genes in the DCM pathway, the activity and function of Cacnald in the hypothalamus was not well-understood. Cacna1d encodes the voltage-gated L-type $\mathrm{Ca}^{2+}$ channel formed by a1D subunits. $\mathrm{Ca}^{2+}$ channel involvement in cardiovascular function is known. For example, mice deficient of the alpha1D subunit of the $\mathrm{Ca}^{2+}$ channel showed bradycardia and arrhythmia as a result of the sinoatrial node dysfunction [68-70]. D-LTCC channels are present in the atrial tissues of the heart where it contributes to pace-making [68]. D-LTCC channel opening results in $\mathrm{Ca}^{2+}$ influx, which activities ryanodine receptor, thus mediating $\mathrm{Ca}^{2+}$ release from intracellular $\mathrm{Ca}^{2+}$ stores such as sarcoplasmic reticulum [71], leading to cardiac muscle contraction. In the brain, D-LTCC channels are important in regulating neuronal activity $[72,73]$. In hippocampus, for example, these channels are involved in both long-term potentiation and long-term depression by coupling with ryanodine receptors [74]. These $\mathrm{Ca}^{2+}$ channel functions in the hypothalamus are little understood, however.

\section{Potential relationship between the hypothalamic gene regulation pattern and alcohol-induced cardiovascular disease}

Regarding hypothalamic gene expression influenced by alcohol, there lacks reported studies about the four SPIF genes we studied. Based on the above-cited evidence of hypothalamus involvement in cardiovascular function, and of the hypothesized involvement of some of these genes in cardiovascular diseases, it is possible that the alcohol-mediated gene down-regulation in the hypothalamus that we observed is related to alcohol-induced cardiovascular disease. Our hypothesis is based on the following considerations:

1. Hypothalamus is a key CNS site for cardiovascular regulation. Hypothalamus is involved in many functions of the sympathetic nervous system, which tightly regulates cardiovascular activity [75-78]. Therefore, changes in hypothalamic gene expression are likely to influence the cardiovascular system, including cardiac muscles. Our study documented hypothalamic gene expression changes in the DCM pathway brought on by chronic alcohol consumption. Given the key role that hypothalamus plays in sympathetic regulation of cardiovascular function, the concerted gene down regulation pattern that we observed in hypothalamus is likely to be involved in regulating cardiovascular function.

2. Chronic alcohol intake can lead to cardiac muscle damage in human and animals, resulting in alcohol-induced cardiac muscle diseases, even heart failure. In dilated cardiomyopathy and heart failure patients, sympathetic system activation and cardiac $\beta-1$ adrenergic receptor down regulation are important characteristics of end-stage dilated cardiomyopathy and heart failure [79-81]. Alcohol can activate the sympathetic nervous system, leading to down regulation of cardiac $\beta A R, G$ s, and $A C$ in human alcoholics and rats consuming chronic alcohol [60-63]. This is consistent with our observation that in the hypothalamus of chronic alcohol-drinking mice, the SPIFs of the DCM pathway showed concerted down regulation. Thus, chronic alcoholic intake leads to the DCM pathway SPIF down regulation in both the hypothalamus and the cardiovascular system. These results suggest that the SPIFs of the DCM pathway may play an important role in the development and progression of alcohol-mediated cardiovascular system injury and diseases (such as alcohol induced cardiac disease and heart failure).

3. Cacnald codes for the dihydropyridine receptor (DHPR), which functions as a $\mathrm{Ca} 2+$ channel to affect $\mathrm{Ca} 2+$ influx across the cell membrane. In Cacnald partial knockout mice, heart dysfunction was reported [68-70]. In neurons, $\mathrm{Ca} 2+$ channels mediate depolarization-induced $\mathrm{Ca} 2+$ influx across the plasma membrane of excitable cells, thus regulating the key physiological processes $[68,82]$. There is no prior report of alcohol-induced Cacna1d down regulation in the hypothalamus. In our study, the concerted down regulation of the SPIF genes in the hypothalamus includes Cacna1d. It is possible that decreased synaptic transmission and neuropeptide secretion in the hypothalamus may influence cardiovascular functions. 
4. Epidemiological studies indicate that alcoholics who consume over $90 \mathrm{~g}$ of alcohol a day for over five years are at high risk for developing asymptomatic DCM; those who continue to drink alcohol for over 15 years may experience symptomatic DCM, leading to potential heart failure $[83,84]$. It is observed that with chronic alcohol consumption, metabolic changes occur within a few weeks $[85,86]$, but signs of depressed contractile function are detectable only after several months of alcohol consumption $[87,88]$.

In our study, the amount of alcohol consumed by mice is in the range of moderate levels, lasting about seven weeks. DCM pathway gene expression is already influenced in the hypothalamus under such conditions. This indicates two issues: (a) the drinking activities spanned the adolescence development, highlighting the danger of adolescent alcohol consumption even at moderate levels, and the potential harmful effect later in adulthood for cardiovascular function; and (b) gene activity changes in the hypothalamus may precede noticeable changes in body's physiology and function, suggesting that these changes in DCM pathway genes may serve as early warning signs for alcohol's harmful effect.

It should be pointed out that hypothalamus is a neuroanatomically heterogeneous brain structure, with various nuclei subserving diverse functions. Samples in our study encompassed much of the hypothalamus, therefore potentially diluting the extent of local gene expression changes. Future studies with more localized brain tissue collection will be helpful to delineate the roles of sub-hypothalamic regions in alcohol consumption and gene modulation. Another point to note is that, although the observed differences in alcohol consumption were not statistically significant between the $5 \%$ and $10 \%$ groups of mice, there still might be subtle differences in related gene expression changes, but our study design did not allow for distinguishing expression changes that are related to the $5 \%$ vs. $10 \%$ alcohol groups. Further studies with larger group sizes would offer improved opportunities to distinguish gene expression differences between different alcohol concentration groups. Additional limitations of this study relate to the fact that only hypothalamic tissues of the brain were studied for gene expression changes; it would be beneficial in future studies to examine cardiac tissues for alcohol-affected genes observed in this study, as a way to validate the findings of the present study. Another issue of note is that in our study, access to alcohol by mice was allowed to continue throughout the study, without any washout period. This study design was chosen to avoid any potential complication from alcohol withdrawal effect, both behaviorally and at the gene expression level, that would likely to occur if a no-drinking washout period were to be instituted. Thus, because of the continued access to alcohol, acute alcohol actions may contribute to the results observed in this study.

\section{Conclusions}

This study showed that chronic alcohol consumption during adolescence, even at moderate levels, may trigger gene expression changes in the CNS that parallel those found in dilated cardiomyopathy (DCM). If such effects also take place in humans, our findings would serve as a warning against alcohol intake in youth, such as by teens and/or college students.

\section{Methods \\ Animals}

Male ICR (Institute for Cancer Research) outbred mice were obtained from Shanghai Laboratory Animal Center, Chinese Academy of Sciences, Shanghai, China. ICR outbred mice were also known as CD-1 (Caesarean Derived1 ), and it is a commonly used outbred mouse strain. Animals were singly-housed in temperature controlled animal facilities on a $12 \mathrm{hr}: 12 \mathrm{hr}$ light-dark cycle with food and water available ad libitum. Recording of water/alcohol consumption was conducted during the light cycle, about 4 hours after the light cycle began. Also, behavioral tests were conducted during the light cycle, beginning 3 hours after the light cycle began, and concluding no less than 2 hours before the end of the light cycle.

Principles of laboratory animal care were followed in accordance with the Guide for the Care and Use of Laboratory Animals (Institute of Laboratory Animal Resources, 1996), the PRC National Standards for Laboratory Animal Quality, and the Guidelines for the Use of Experimental Animals.

\section{Chronic alcohol self-administration}

For the chronic alcohol drinking experiment, the paradigm of two-bottle choice was used [42]. Each cage was equipped with two drinking tubes. The drinking tubes were made from $10 \mathrm{ml}$ plastic serological pipettes (Coster Stripette), with $0.1 \mathrm{ml}$ graduation. The narrow tip of the pipette was cut off and a stainless steel sipper tube was connected through a silicone tubing. Animal's body weight and the food consumption were measured on weekdays.

Before chronic alcohol drinking began, mice (3 weeks old) were allowed to adapt to the drinking tubes with both tubes containing water from experimental day 1-5. After this adaptation period, mice were randomly assigned to $5 \%$ alcohol group, $10 \%$ alcohol group, or water-only control group $(n=16-18)$. For the water-only control group, two drinking tubes in each cage contained deionized water throughout the duration of the experiment. For the alcohol groups, one drinking tube contained 5\% or $10 \%$ alcohol solution while the other contained water. The amount of the water or alcohol consumption was 
recorded daily. The solution content (water or alcohol) was refreshed every day, and the positions of the two tubes in the cage were switched daily to avoid any side bias.

\section{Motor activities measurement}

Behavior tests began on day 50 of the experiment. For motor activity measurement, an automated beam break detection system (San Diego Instruments) was used as previously described [89]. Animals were placed individually in plastic chambers $(48 \times 24 \times 20 \mathrm{~cm}, \mathrm{LxWxH})$ with bedding material, and the chamber was covered with a piece of glass on the top. Each chamber was placed inside a wooden enclosure $(60 \times 40 \times 44 \mathrm{~cm}, \mathrm{LxWxH})$ that was sound- and light-proof, illuminated from inside with a fluorescence light $(5 \mathrm{~W})$. Motor activity was measured via automated detection of infrared beam breaks. Rearing behavior was detected by a second set of infrared photodetectors mounted $7.7 \mathrm{~cm}$ above the ground.

\section{RNA extraction and DNA microarray}

Chronic alcohol drinking lasted to day 57 of the experiment without any change and interruption. Then each mouse is sacrificed by decapitation, and the hypothalamus was dissected for rapid freeze and storage at $-80^{\circ} \mathrm{C}$. Hypothalamus tissue samples were used for total RNA extraction.

Total RNA was isolated using the TRIzol reagent (Invitrogen, Carlsbad, CA) and purified with RNeasy column (Qiagen, Valencia, CA). RNA concentration and purity were analyzed with Nanodrop spectrophotometer (Nanodrop Technologies, Wilmington, DE), with the spectral absorption at 260 and $280 \mathrm{~nm}$. RNA integrity was assessed with Bioanalyzer 2100 (Agilent Technologies, Palo Alto, CA). All RNA samples had RNA Integrity Numbers (RIN) of 8.4 or higher and $28 \mathrm{~S} / 18 \mathrm{~S}$ ratio of 1.5 or higher.

RNA samples were pooled for microarray. For wateronly group, nine mice were used to make three pools, with three equal amounts of RNA samples per pool. For alcohol group, nineteen mice were used to make nine pools, with one to three equal RNA samples per pool, where samples A1-A3 had mice with relatively less alcohol consumed and samples A4-A9 had mice with relatively more alcohol consumed (Additional file 4: Table S3).

The microarray study was carried out as mono-color experiment. Total RNA was Cy3 labeled according to Agilent's Low RNA Input Fluorescent Linear Amplification Kit and hybridized onto Agilent Whole Mouse Genome $4 \times 44 \mathrm{~K}$ G4122F microarrays containing 43,604 probes as described in the manufacturer's protocol. Slides were scanned (Agilent G2505B) at $5 \mu \mathrm{m}$ resolution using an extended dynamic range protocol, and images were processed with Agilent Feature Extraction software 9.5. Within-array normalization was performed using the
"Background detrending" software (Agilent). The nonuniform outlier features (spots) were removed and the intensity values were transformed to a log base 2 scale. The microarray data have been deposited in Gene Expression Omnibus with the accession code GSE42770.

\section{Microarray data analysis}

The spots with low signal noise ratio $(<2)$ were automatically eliminated, and only "perfect value" of those genes present in $>50 \%$ samples in each group were applied in further analysis. Principal component analysis (PCA) was used to summarize gene expression profiles between groups. Differentially expressed genes (DEGs) were determined by comparing with the control group, using a corresponding $t$-test with the significance level set at $p$-value $<0.05$ and $q$-value (false discover rate) at $<0.05$ [90]. Hierarchical clustering and visualization were performed using Cluster 3.0 and TreeView software (M. B. Eisen Laboratory, Stanford University, Stanford, CA). Average linkage with the uncentered correlation similarity metric was used for the clustering of samples. Pathway analysis was carried out using DAVID Functional Classification tool [91], the open source pathway resources of Kyoto Encyclopedia of Genes and Genomes (KEGG) (http://www.genome.jp/kegg/) [92], and the Web-based Gene Set Analysis Toolkit (WebGestalt) [93].

\section{Real-time PCR}

Based on our analysis of significant biological pathways that are associated with the identified differentially expressed genes, real-time PCR was used to verify the status of differential expression and to exclude false positives. For internal control, we initially evaluated two genes ( $\beta$-actin and glyceraldehyde-3-phosphate dehydrogenase, or Gapdh). Both $\beta$-actin and Gapdh showed stable expression in each sample in the microarray, therefore they both qualified as internal control at this point. From there, we used qRT-PCR to measure both genes' expression levels in our samples (C1-C3, A1-A9), utilizing the NormFinder program [94]. The NormFinder software adopts a modelbased variance estimation approach to identify genes suited for normalization, and provides a rank order according to gene's expression stability. According to this program, $\beta$-actin was identified as the more stably expressed gene, and was therefore selected as reference gene for gene expression normalization in the qRT-PCR experiment. The sequences of the primers for the target genes and the internal control gene ( $\beta$-actin) are listed in Additional file 5: Table S2.

For cDNA synthesis, oligo(dT) primers, $2 \mu \mathrm{g}$ of each total RNA sample used in microarray experiment, and the Superscript II reverse transcriptase (Invitrogen) were used, following the guidelines of the manufacturer. cDNA samples were placed on ice and stored at $-20^{\circ} \mathrm{C}$ until 
further use. Prior to the analysis, $20 \mu \mathrm{l}$ of each cDNA sample was diluted with $360 \mu \mathrm{l}$ of MilliQ water. qPCR reactions were performed with the Prism 7900 Sequence Detection System (Applied Biosystems, Foster City, CA). For each reaction, $1 \mu \mathrm{l}$ of each diluted cDNA sample was added to a mixture containing $10 \mu \mathrm{l}$ of $2 \times$ SYBR green II qRT-PCR kit (Toyobo, Osaka, Japan), $1 \mu \mathrm{l}$ of each primer $(5 \mu \mathrm{M})$, and $8 \mu \mathrm{l}$ of MilliQ water. Cycling conditions were $10 \mathrm{~min} 95^{\circ} \mathrm{C}$, followed by 40 cycles of $15 \mathrm{~s}$ at $95^{\circ} \mathrm{C}$ and $1 \mathrm{~min}$ at $60^{\circ} \mathrm{C}$. After cycling, a melting protocol was performed with $15 \mathrm{~s}$ at $95^{\circ} \mathrm{C}, 1 \mathrm{~min}$ at $60^{\circ} \mathrm{C}$, and $15 \mathrm{~s}$ at $95^{\circ} \mathrm{C}$, to control for product specificity.

The fold change (FC) in target gene cDNA relative to selected endogenous control gene was determined as follows: $\mathrm{FC}=2^{-\Delta \Delta \mathrm{Ct}}$, where $\Delta \Delta \mathrm{Ct}=\left(\mathrm{Ct}_{\text {Target }}-\mathrm{Ct}_{\text {Control }}\right)$ test $-\left(\mathrm{Ct}_{\text {Target }}-\mathrm{Ct}_{\text {Control }}\right)$ control. $\mathrm{Ct}$ values were defined as the number of the PCR cycles at which the fluorescence signals were detected. In qRT-PCR analysis, data are presented as mean \pm SEM and analyzed with $t$-test by SPSS 13.0 (SPSS Inc, Chicago, IL).

\section{Statistics}

Repeated measures two-way ANOVA with Bonferroni post tests was used to compare the two chronic alcohol groups (5\% and $10 \%)$ in daily alcohol consumption. Repeated measures ANOVA with post test of Dunnett's multiple comparison test was used to compare daily alcohol consumption between the first time point and other time points. Unpaired t-test was used to compare the chronic alcohol and water-only control mice in locomotion and rearing behavior.

\section{Additional files}

Additional file 1: Table S1. List of differentially expressed genes identified in microarray analysis between chronic alcohol consumption and water-only control.

Additional file 2: Figure S1. Heat map of genes differentially expressed between chronic alcohol vs. control mouse hypothalamus samples. Gene expression values are color-coded according to the scale on the right. Displayed on top is the clustering display of differentially expressed genes using the unsupervised hierarchical clustering method. C1-C3: water-only control samples; A1-A9: chronic alcohol samples.

Additional file 3: Table S4. Top 5 pathways from DAVID Functional Classification Analysis and Web-based Gene Set Analysis.

Additional file 4: Table S3. Pooling of RNA samples from alcohol mice. Additional file 5: Table S2. Sequences of primers for qRT-PCR.

\section{Competing interests}

The authors declare that they have no competing interests.

\section{Authors' contributions}

$\mathrm{HZ}$, study design, literature search, chronic alcohol experiment, behavior experiment, behavior data analysis, statistical analysis, writing of the manuscript. KW, microarray gene expression experiment and data analysis, RT-PCR, statistical analysis, writing of the manuscript. YG and HS, microarray gene expression experiment and data analysis, RT-PCR. QX, chronic alcohol experiment, behavior experiment. MJ and GZ, study design, editing of the manuscript. HX, study design, microarray gene expression experiment and data analysis, editing of the manuscript. LY, study design, data analysis, writing manuscript, supervision of the study. All authors contributed to and have approved the final manuscript.

\section{Acknowledgements}

We thank Libo Lin for assistance with DNA microarray hybridization.

\section{Author details}

${ }^{1}$ Shanghai Institutes for Biological Sciences, Chinese Academy of Sciences, Shanghai, China. ${ }^{2}$ State Key Laboratory of Genetic Engineering, Department of Microbiology, School of Life Sciences and Institute of Biomedical Sciences, Fudan University, Shanghai, China. ${ }^{3}$ Shanghai-MOST Key Laboratory of Disease and Health Genomics, Chinese National Human Genome Center at Shanghai, National Engineering Research Center for Biochip at Shanghai, Shanghai, China. ${ }^{4}$ Shu Guang Hospital affiliated with the Shanghai Traditional Medicine University, Shanghai, China. ${ }^{5}$ Department of Microbiology and Li Ka Shing Institute of Health Sciences, The Chinese University of Hong Kong, Prince of Wales Hospital, Hong Kong, SAR, China. ${ }^{6}$ Department of Genetics \& Center of Alcohol Studies, Rutgers University, 607 Allison Road, Piscataway, New Jersey 08854, USA.

Received: 3 September 2013 Accepted: 23 April 2014 Published: 9 May 2014

\section{References}

1. White AM, Swartzwelder HS: Hippocampal function during adolescence: a unique target of ethanol effects. Ann N Y Acad Sci 2004, 1021:206-220.

2. Spear LP, Varlinskaya El: Adolescence. Alcohol sensitivity, tolerance, and intake. Recent DevAlcohol 2005, 17:143-159.

3. Yamaguchi K, Kandel DB: Patterns of drug use from adolescence to young adulthood: III. Predictors of progression. Am J Public Health 1984, 74(7):673-681.

4. Robins LN, Przybeck TR: Age of onset of drug use as a factor in drug and other disorders. NIDA Res Monogr 1985, 56:178-192.

5. Deykin EY, Levy JC, Wells V: Adolescent depression, alcohol and drug abuse. Am J Public Health 1987, 77(2):178-182.

6. Grant BF, Dawson DA: Age at onset of alcohol use and its association with DSM-IV alcohol abuse and dependence: results from the National Longitudinal Alcohol Epidemiologic Survey. J Subst Abuse 1997, 9:103-110.

7. Hawkins JD, Graham JW, Maguin E, Abbott R, Hill KG, Catalano RF: Exploring the effects of age of alcohol use initiation and psychosocial risk factors on subsequent alcohol misuse. J Stud Alcohol 1997, 58(3):280-290.

8. Oscar-Berman M, Marinkovic K: Alcohol: effects on neurobehavioral functions and the brain. Neuropsychol Rev 2007, 17(3):239-257.

9. Lebel C, Roussotte F, Sowell ER: Imaging the impact of prenatal alcohol exposure on the structure of the developing human brain. Neuropsychol Rev 2011, 21(2):102-118.

10. Zahr NM, Kaufman KL, Harper CG: Clinical and pathological features of alcohol-related brain damage. Nat Rev Neurol 2011, 7(5):284-294.

11. Schulte T, Oberlin BG, Kareken DA, Marinkovic K, Muller-Oehring EM, Meyerhoff DJ, Tapert S: How acute and chronic alcohol consumption affects brain networks: insights from multimodal neuroimaging. Alcohol Clin Exp Res 2012, 36(12):2017-2027.

12. Gao B, Bataller R: Alcoholic liver disease: pathogenesis and new therapeutic targets. Gastroenterology 2011, 141(5):1572-1585.

13. George A, Figueredo VM: Alcoholic cardiomyopathy: a review. J Card Fail 2011, 17(10):844-849.

14. Giacosa A, Adam-Blondon AF, Baer-Sinnott $S$, Barale R, Bavaresco L, Di Gaspero G, Dugo L, Ellison RC, Gerbi V, Gifford D, Janssens J, La Vecchia C, Negri E, Pezzotti M, Santi L, Rondanelli M: Alcohol and wine in relation to cancer and other diseases. Eur J Cancer Prev 2012, 21(1):103-108.

15. Vilpoux C, Warnault V, Pierrefiche O, Daoust M, Naassila M: Ethanol-sensitive brain regions in rat and mouse: a cartographic review, using immediate early gene expression. Alcohol Clin Exp Res 2009, 33(6):945-969.

16. Anand BK, Brobeck JR: Localization of a "feeding center" in the hypothalamus of the rat. Proc Soc Exp Biol Med 1951, 77:323-324.

17. Hetherington AW, Ranson SW: Hypothalamic lesions and adiposity in the rat. Anat Rec 1940, 78(2):149-172. 
18. Barson JR, Morganstern I, Leibowitz SF: Similarities in hypothalamic and mesocorticolimbic circuits regulating the overconsumption of food and alcohol. Physiol Behav 2011, 104(1):128-137.

19. DiLeone RJ, Georgescu D, Nestler EJ: Lateral hypothalamic neuropeptides in reward and drug addiction. Life Sci 2003, 73(6):759-768.

20. Harris GC, Wimmer M, Aston-Jones G: A role for lateral hypothalamic orexin neurons in reward seeking. Nature 2005, 437(7058):556-559.

21. Marchant NJ, Millan EZ, McNally GP: The hypothalamus and the neurobiology of drug seeking. Cell Mol Life Sci 2012, 69(4):581-597.

22. Wayner MJ, Greenberg I, Carey RJ, Nolley D: Ethanol drinking elicited during electrical stimulation of the lateral hypothalamus. Physiol Behav 1971, 7(5):793-795.

23. Amit Z, Meade RG, Corcoran ME: The lateral hypothalamus, catecholamines and ethanol self-administration in rats. Adv Exp Med Biol 1975, 59:311-321.

24. Leibowitz SF: Overconsumption of dietary fat and alcohol: mechanisms involving lipids and hypothalamic peptides. Physiol Behav 2007, 91(5):513-521.

25. Barson JR, Carr AJ, Soun JE, Sobhani NC, Rada P, Leibowitz SF, Hoebel BG: Opioids in the hypothalamic paraventricular nucleus stimulate ethanol intake. Alcohol Clin Exp Res 2010, 34(2):214-222.

26. Morganstern I, Chang GQ, Chen YW, Barson JR, Zhiyu Y, Hoebel BG, Leibowitz SF: Role of melanin-concentrating hormone in the control of ethanol consumption: Region-specific effects revealed by expression and injection studies. Physiol Behav 2010, 101(4):428-437.

27. McCaul ME, Wand GS, Stauffer R, Lee SM, Rohde CA: Naltrexone dampens ethanol-induced cardiovascular and hypothalamic- pituitary-adrenal axis activation. Neuropsychopharmacology 2001, 25(4):537-547.

28. Rivier C: Alcohol stimulates ACTH secretion in the rat: mechanisms of action and interactions with other stimuli. Alcohol Clin Exp Res 1996, 20(2):240-254

29. Wand GS, Dobs AS: Alterations in the hypothalamic-pituitary-adrenal axis in actively drinking alcoholics. J Clin Endocrinol Metab 1991, 72(6):1290-1295.

30. Allen CD, Lee S, Koob GF, Rivier C: Immediate and prolonged effects of alcohol exposure on the activity of the hypothalamic-pituitary-adrenal axis in adult and adolescent rats. Brain Behav Immun 2011 25(Suppl 1):S50-S60.

31. Erritzoe D, Tziortzi A, Bargiela D, Colasanti A, Searle GE, Gunn RN, Beaver JD, Waldman A, Nutt DJ, Bani M, Merlo-Pich E, Rabiner EA, Lingford-Hughes A: In Vivo Imaging of Cerebral Dopamine D3 Receptors in Alcoholism. Neuropsychopharmacology 2014. Epub ahead of print.

32. Dees WL, Srivastava VK, Hiney JK: Alcohol alters insulin-like growth factor-1 activated oct 2 POU domain gene expression in the immature female hypothalamus. J Stud Alcohol 2005, 66(1):35-45.

33. Srivastava VK, Hiney JK, Dees WL: Short-term alcohol administration alters KiSS-1 gene expression in the reproductive hypothalamus of prepubertal female rats. Alcohol Clin Exp Res 2009, 33(9):1605-1614

34. Bekdash RA, Zhang C, Sarkar DK: Gestational choline supplementation normalized fetal alcohol-induced alterations in histone modifications, DNA methylation, and proopiomelanocortin (POMC) gene expression in beta-endorphin-producing POMC neurons of the hypothalamus. Alcohol Clin Exp Res 2013, 37(7):1133-1142.

35. Agapito MA, Barreira JC, Logan RW, Sarkar DK: Evidence for possible period 2 gene mediation of the effects of alcohol exposure during the postnatal period on genes associated with maintaining metabolic signaling in the mouse hypothalamus. Alcohol Clin Exp Res 2013, 37(2):263-269

36. Ryabinin AE, Criado JR, Henriksen SJ, Bloom FE, Wilson MC: Differential sensitivity of c-Fos expression in hippocampus and other brain regions to moderate and low doses of alcohol. Mol Psychiatry 1997, 2(1):32-43.

37. Ryabinin $A E$, Wang YM: Repeated alcohol administration differentially affects c-Fos and FosB protein immunoreactivity in DBA/2 J mice. Alcohol Clin Exp Res 1998, 22(8):1646-1654.

38. Ahmed SH, Lutjens R, van der Stap LD, Lekic D, Romano-Spica V, Morales M, Koob GF, Repunte-Canonigo V, Sanna PP: Gene expression evidence for remodeling of lateral hypothalamic circuitry in cocaine addiction. Proc Natl Acad Sci U S A 2005, 102(32):11533-11538.

39. Chen H, Saad S, Sandow SL, Bertrand PP: Cigarette smoking and brain regulation of energy homeostasis. Front Pharmacol 2012, 3:147.

40. Cohn JN, Levine TB, Olivari MT, Garberg V, Lura D, Francis GS, Simon AB, Rector T: Plasma norepinephrine as a guide to prognosis in patients with chronic congestive heart failure. N Engl J Med 1984, 311(13):819-823.
41. Brum PC, Rolim NP, Bacurau AV, Medeiros A: Neurohumoral activation in heart failure: the role of adrenergic receptors. An Acad Bras Cienc 2006, 78(3):485-503.

42. Zou H, Xie Q, Zhang M, Zhang C, Zhao G, Jin M, Yu L: Chronic alcoho consumption from adolescence to adulthood in mice - effect on growth and social behavior. Drug Alcohol Depend 2009, 104:119-125.

43. Randall CL, Carpenter JA, Lester D, Friedman HJ: Ethanol-induced mouse strain differences in locomotor activity. Pharmacol Biochem Behav 1975, 3(3):533-535.

44. Frye GD, Breese GR: An evaluation of the locomotor stimulating action of ethanol in rats and mice. Psychopharmacology (Berl) 1981, 75(4):372-379.

45. Tambour S, Didone V, Tirelli E, Quertemont E: Locomotor effects of ethanol and acetaldehyde after peripheral and intraventricular injections in Swiss and C57BL/6 J mice. Behav Brain Res 2006, 172(1):145-154.

46. Rhodes JS, Ford MM, Yu CH, Brown LL, Finn DA, Garland T Jr, Crabbe JC: Mouse inbred strain differences in ethanol drinking to intoxication. Genes Brain Behav 2007, 6(1):1-18.

47. Short JL, Drago J, Lawrence AJ: Comparison of ethanol preference and neurochemical measures of mesolimbic dopamine and adenosine systems across different strains of mice. Alcohol Clin Exp Res 2006, 30(4):606-620.

48. McMillen BA, Williams HL: Role of taste and calories in the selection of ethanol by C57BL/6NHsd and Hsd:ICR mice. Alcohol 1998, 15(3):193-198.

49. Belknap JK, Crabbe JC, Young ER: Voluntary consumption of ethanol in 15 inbred mouse strains. Psychopharmacology (Berlin) 1993, 112(4):503-510.

50. Grisel JE, Mogil JS, Grahame NJ, Rubinstein M, Belknap JK, Crabbe JC, Low MJ: Ethanol oral self-administration is increased in mutant mice with decreased beta-endorphin expression. Brain Res 1999, 835(1):62-67.

51. Middaugh LD, Bandy AL: Naltrexone effects on ethanol consumption and response to ethanol conditioned cues in C57BL/6 mice.

Psychopharmacology (Berlin) 2000, 151(4):321-327.

52. Roberts AJ, Gold LH, Polis I, McDonald JS, Filliol D, Kieffer BL, Koob GF: Increased ethanol self-administration in delta-opioid receptor knockout mice. Alcohol ClinExpRes 2001, 25(9):1249-1256.

53. Spanagel R, Siegmund S, Cowen M, Schroff KC, Schumann G, Fiserova M, Sillaber I, Wellek S, Singer M, Putzke J: The neuronal nitric oxide synthase gene is critically involved in neurobehavioral effects of alcohol. J Neurosci 2002, 22(19):8676-8683.

54. Blizard DA, Vandenbergh DJ, Jefferson AL, Chatlos CD, Vogler GP, McClearn GE: Effects of periadolescent ethanol exposure on alcohol preference in two BALB substrains. Alcohol 2004, 34(2-3):177-185.

55. Camarini R, Hodge CW: Ethanol preexposure increases ethanol self-administration in $\mathrm{C} 57 \mathrm{BL} / 6 \mathrm{~J}$ and DBA/2 J mice. Pharmacol Biochem Behav 2004, 79(4):623-632.

56. Khisti RT, Wolstenholme J, Shelton KL, Miles MF: Characterization of the ethanol-deprivation effect in substrains of C57BL/6 mice. Alcohol 2006, 40(2):119-126.

57. Center for Drug Evaluation and Research FDA: Guidance for industry: estimating the maximum safe starting dose in initial clinical trials for therapeutics in adult healthy volunteers. Silver Spring, MD, U.S: Food and Drug Administration; 2005.

58. Ozawa H, Katamura Y, Hatta S, Saito T, Katada T, Gsell W, Froelich L, Takahata N, Riederer P: Alterations of guanine nucleotide-binding proteins in post-mortem human brain in alcoholics. Brain Res 1993, 620(1):174-179.

59. Sohma H, Hashimoto E, Shirasaka T, Tsunematsu R, Ozawa H, Boissl KW, Boning J, Riederer P, Saito T: Quantitative reduction of type I adenylyl cyclase in human alcoholics. Biochim Biophys Acta 1999, 1454(1):11-18.

60. Diamond I, Wrubel B, Estrin W, Gordon A: Basal and adenosine receptor-stimulated levels of CAMP are reduced in lymphocytes from alcoholic patients. Proc Natl Acad Sci U S A 1987, 84(5):1413-1416.

61. Tabakoff B, Hoffman PL, Lee JM, Saito T, Willard B, De Leon-Jones F: Differences in platelet enzyme activity between alcoholics and nonalcoholics. N Engl J Med 1988, 318(3):134-139.

62. Koga Y, Kajiyama K, Sufu H, Otsuki T, Tsuji Y, Iwami G, Toshima H: Alterations in beta-adrenergic receptor density and cyclic-AMP level in the myocardium of rats chronically treated with alcohol. Kurume Med J 1993, 40(1):1-6.

63. Banerjee SP, Sharma VK, Khanna JM: Alterations in beta-adrenergic receptor binding during ethanol withdrawal. Nature 1978, 276(5686):407-409.

64. French SW, Palmer DS, Narod ME, Reid PE, Ramey CW: Noradrenergic sensitivity of the cerebral cortex after chronic ethanol ingestion and withdrawal. J Pharmacol Exp Ther 1975, 194(2):319-326. 
65. Saito T, Lee JM, Hoffman PL, Tabakoff B: Effects of chronic ethanol treatment on the beta-adrenergic receptor-coupled adenylate cyclase system of mouse cerebral cortex. J Neurochem 1987, 48(6):1817-1822.

66. Wand GS, Levine MA: Hormonal tolerance to ethanol is associated with decreased expression of the GTP-binding protein, Gs alpha, and adenylyl cyclase activity in ethanol-treated LS mice. Alcohol Clin Exp Res 1991 15(4):705-710

67. Wand GS, Diehl AM, Levine MA, Wolfgang D, Samy S: Chronic ethanol treatment increases expression of inhibitory G-proteins and reduces adenylylcyclase activity in the central nervous system of two lines of ethanol-sensitive mice. J Biol Chem 1993, 268(4):2595-2601.

68. Platzer J, Engel J, Schrott-Fischer A, Stephan K, Bova S, Chen H, Zheng H, Striessnig J: Congenital deafness and sinoatrial node dysfunction in mice lacking class D L-type Ca2+ channels. Cell 2000, 102(1):89-97.

69. Zhang $Z, X u Y$, Song $H$, Rodriguez J, Tuteja D, Namkung $Y$, Shin HS, Chiamvimonvat N: Functional Roles of $\mathrm{Ca}(\mathrm{v}) 1.3$ (alpha(1D)) calcium channel in sinoatrial nodes: insight gained using gene-targeted null mutant mice. Circ Res 2002, 90(9):981-987.

70. Mangoni ME, Couette B, Bourinet E, Platzer J, Reimer D, Striessnig J, Nargeot J: Functional role of L-type Cav1.3 Ca2+ channels in cardiac pacemaker activity. Proc Natl Acad Sci U S A 2003, 100(9):5543-5548.

71. Bers DM: Cardiac excitation-contraction coupling. Nature 2002, 415(6868):198-205.

72. Hell JW, Westenbroek RE, Warner C, Ahlijanian MK, Prystay W, Gilbert MM, Snutch TP, Catterall WA: Identification and differential subcellular localization of the neuronal class C and class D L-type calcium channel alpha 1 subunits. J Cell Biol 1993, 123(4):949-962.

73. Safa P, Boulter J, Hales TG: Functional properties of Cav1.3 (alpha1D) L-type Ca2+ channel splice variants expressed by rat brain and neuroendocrine GH3 cells. J Biol Chem 2001, 276(42):38727-38737.

74. Kim S, Yun HM, Baik JH, Chung KC, Nah SY, Rhim H: Functional interaction of neuronal Cav1.3 L-type calcium channel with ryanodine receptor type 2 in the rat hippocampus. J Biol Chem 2007, 282(45):32877-32889.

75. Hilton SM: Hypothalamic regulation of the cardiovascular system. Br Med Bull 1966, 22(3):243-248.

76. Coote $\mathrm{JH}$ : Cardiovascular function of the paraventricular nucleus of the hypothalamus. Biol Signals 1995, 4(3):142-149.

77. Ferguson AV, Latchford KJ, Samson WK: The paraventricular nucleus of the hypothalamus - a potential target for integrative treatment of autonomic dysfunction. Expert Opin Ther Targets 2008, 12(6):717-727.

78. Pyner S: Neurochemistry of the paraventricular nucleus of the hypothalamus: implications for cardiovascular regulation. $J$ Chem Neuroanat 2009, 38(3):197-208

79. Bristow MR, Ginsburg R, Minobe W, Cubicciotti RS, Sageman WS, Lurie K Billingham ME, Harrison DC, Stinson EB: Decreased catecholamine sensitivity and beta-adrenergic-receptor density in failing human hearts. N Engl J Med 1982, 307(4):205-211.

80. Bristow MR, Minobe WA, Raynolds MV, Port JD, Rasmussen R, Ray PE, Feldman AM: Reduced beta 1 receptor messenger RNA abundance in the failing human heart. J Clin Invest 1993, 92(6):2737-2745.

81. Lohse MJ, Engelhardt S, Eschenhagen $\mathrm{T}$ : What is the role of betaadrenergic signaling in heart failure? Circ Res 2003, 93(10):896-906.

82. Lipscombe D, Helton TD, Xu W: L-type calcium channels: the low down. J Neurophysiol 2004, 92(5):2633-2641.

83. Piano MR: Alcoholic cardiomyopathy: incidence, clinical characteristics, and pathophysiology. Chest 2002, 121(5):1638-1650.

84. Laonigro I, Correale M, Di Biase M, Altomare E: Alcohol abuse and heart failure. Eur J Heart Fail 2009, 11(5):453-462.

85. Solem M, Almas J, Rubin E, Thomas A: Changes in activity and regulation of the cardiac Ca2+ channel (L-type) by protein kinase $\mathrm{C}$ in chronic alcohol-exposed rats. Alcohol Clin Exp Res 2000, 24(8):1145-1152.

86. Pecherskaya A, Rubin E, Solem M: Alterations in insulin-like growth factor-I signaling in cardiomyocytes from chronic alcohol-exposed rats. Alcohol Clin Exp Res 2002, 26(7):995-1002.

87. Thomas G, Haider B, Oldewurtel HA, Lyons MM, Yeh CK, Regan TJ: Progression of myocardial abnormalities in experimental alcoholism. Am J Cardiol 1980, 46(2):233-241.

88. Thomas AP, Rozanski DJ, Renard DC, Rubin E: Effects of ethanol on the contractile function of the heart: a review. Alcohol Clin Exp Res 1994, 18(1):121-131.
89. Wu J, Zou H, Strong JA, Yu J, Zhou X, Xie Q, Zhao G, Jin M, Yu L: Bimodal effects of MK-801 on locomotion and stereotypy in C57BL/6 mice. Psychopharmacology 2005, 177(3):256-263

90. Casella G, Berger R: Statistical Inference. 2nd edition. Pacific Grove: Wadsworth; 2002.

91. Huang DW, Sherman BT, Lempicki RA: Systematic and integrative analysis of large gene lists using DAVID bioinformatics resources. Nat Protoc 2009, 4(1):44-57.

92. Ogata H, Goto S, Sato K, Fujibuchi W, Bono H, Kanehisa M: KEGG: Kyoto Encyclopedia of Genes and Genomes. Nucleic Acids Res 1999, 27(1):29-34

93. Zhang B, Schmoyer D, Kirov S, Snoddy J: GOTree Machine (GOTM): a web-based platform for interpreting sets of interesting genes using Gene Ontology hierarchies. BMC Bioinforma 2004, 5:16.

94. Andersen $\mathrm{CL}$, Jensen $J$, Orntoft TF: Normalization of real-time quantitative reverse transcription-PCR data: a model-based variance estimation approach to identify genes suited for normalization, applied to bladder and colon cancer data sets. Cancer Res 2004, 64(15):5245-5250.

doi:10.1186/1471-2202-15-61

Cite this article as: Zou et al:: Chronic alcohol consumption from adolescence-to-adulthood in mice - hypothalamic gene expression changes in the dilated cardiomyopathy signaling pathway. BMC Neuroscience 2014 15:61.

\section{Submit your next manuscript to BioMed Central and take full advantage of:}

- Convenient online submission

- Thorough peer review

- No space constraints or color figure charges

- Immediate publication on acceptance

- Inclusion in PubMed, CAS, Scopus and Google Scholar

- Research which is freely available for redistribution 